POLLACK PERIODICA

An International Journal for Engineering and Information Sciences

DOI: $10.1556 / 606.2016 .11 .1 .6$

Vol. 11, No. 1, pp. 55-66 (2016)

www.akademiai.com

\title{
COMPARISON OF EMPIRICAL LIQUEFACTION POTENTIAL EVALUATION METHODS
}

\author{
${ }^{1}$ Zoltán BÁN, ${ }^{2}$ Tamás János KATONA, ${ }^{3}$ András MAHLER \\ ${ }^{1,3}$ Department of Geotechnics, Budapest University of Technology and Economics, \\ Budapest, Müegyetem rkp. 3-9. H-1111, Hungary \\ e-mail: ${ }^{1}$ ban.zoltan@epito.bme.hu, ${ }^{3}$ mahler@mail.bme.hu \\ ${ }^{2}$ MVM Nuclear Power Plant Paks LTd, H-7031, Paks, Hungary, e-mail: bata01@t-online.hu
}

Received 1 January 2015; accepted 1 June 2015

\begin{abstract}
Numerous methods exist to determine the liquefaction potential of a site due to earthquake, from which the stress-based empirical methods are the most commonly used in practice. Despite of their widespread use, their shortcomings have given way to the evolution of strain and energy-based methods. Their benefits make them a very promising alternative candidate for liquefaction potential evaluation. To reveal differences and uncertainties involved in the different methods, a comparative analysis was performed for the site of the Paks Nuclear Power Plant with the aim of contributing to the safety assessment of the plant with respect to liquefaction effects.
\end{abstract}

Keywords: Liquefaction, Empirical methods, Nuclear power plant

\section{Introduction}

Nuclear power plants are potentially high-risk facilities therefore they have to be protected against the effects of low probability hazards. The design base level of external events is set to a $10^{-4} /$ year annual probability. The Grand Tohoku earthquake and tsunami, and the subsequent severe nuclear accident of the Fukushima Dai-ichi Nuclear Power Plant, urged the nuclear industry to prepare for all possible hazards, even if their probability is lower than the design basis level. The accident of Fukushima Dai-ichi also drew the attention to the secondary effects of external events. This is the motivation for the evaluation of the effects of liquefaction on the Paks Nuclear Power Plant (Paks NPP). It is the only NPP in Hungary producing more than 40 percent of the domestic electrical power generation. The power plant is located next to the River 
Danube, where mainly fluvial coarse-grained sediments build up the subsoil. These types of soils are among the most susceptible to seismically induced liquefaction in nature. Liquefaction at the site is considered as beyond design basis hazard, therefore the aim of analysis is to assess the possible post-liquefaction scenarios and develop effective accident management measures [1]. This requires comprehensive evaluation of liquefaction susceptibility as well as the effects acting on the structures and lifelines.

Liquefaction potential at a particular site can be assessed either by analytical or empirical methods. The first method attempts to model the soil behavior under seismic loading explicitly in a site response analysis with an appropriate constitutive model. The accuracy of the results depends on the suitability of the constitutive model and on the accuracy of input parameters for the soil model. The main benefit of this approach is that it can trace pore pressure generation during shaking. On the other hand, the input parameters of the model require substantial field and laboratory testing, thus it is mainly used for research and large projects [2].

Empirical procedures are based on correlations between seismic loading and soil resistance to liquefaction. Seismic loading is usually represented by an intensity measure; while liquefaction resistance can be determined using case histories to characterize resistance in the form of measured in situ test parameters, most commonly Standard Penetration Test (SPT) blow-count, Cone Penetration Test (CPT) tip resistance or shear wave velocity. This type of assessment has much wider usage than explicit models, primarily because it is easier and less expensive to implement. Empirical methods fall into three main groups: cyclic stress, cyclic strain and energy concepts.

Nuclear safety regulation prefers the use of consensus-based conservative empirical methods, e.g. the US NRC Regulatory Guide 1.198 refers to the method of Youd et al. [3]. However, contrary to the design, conservatism of the methodology for the evaluation of beyond design basis liquefaction effects for an operating plant has to be limited to a reasonable level. Consequently, the recently developed strain- and energybased methods have to be also applied for best estimation. In the paper comparison of the Peak Ground Acceleration (PGA), Arias intensity and Cumulative Absolute Velocity (CAV)-based empirical methods is presented using geotechnical and seismological information from Paks NPP site.

\section{Empirical liquefaction potential evaluation methods}

The commonly used cyclic stress-based methods calculate the seismic demand in form of equivalent uniform Cyclic Stress Ratio (CSR) as it was first proposed by Seed and Idriss [4]:

$$
C S R=\frac{\tau_{c y c}}{\sigma_{v 0}^{\prime}}=0.65 \cdot \frac{\sigma_{v 0}}{\sigma_{v 0}^{\prime}} \cdot \frac{a_{\max }}{g} \cdot r_{d},
$$

where $\tau_{c y c}$ is the cyclic shear stress; $a_{\max }$ is the maximum horizontal acceleration at the ground surface (PGA); $g$ is the gravitational acceleration; $r_{d}$ is a stress reduction 
coefficient that accounts for the flexibility of the soil column; $\sigma_{v 0}^{\prime}$ is the effective vertical stress and $\sigma_{v 0}$ is the total vertical stress at depth $z$. The $r_{d}$ factor can be estimated most accurately with a detailed site response analysis, or in practice, via simplified equations. CSR is then compared to the Cyclic Resistance Ratio (CRR), which separates liquefaction and non-liquefaction case histories and can be determined from the relevant in situ index, to obtain Factor of Safety (FS). The traditional way of liquefaction potential evaluation is based on SPT blow-counts, as well the energy related methods. In this paper therefore attention was given to the SPT-based methods.

Although the framework of the method has remained the same, several modifications have been presented in the last 20 years. The most recent and elaborated revisions were performed by I. M. Idriss and R. W. Boulanger [5], [6] and at University of California, Berkeley under the supervision of R. B. Seed [7], [8].

Cetin and his coauthors [7] assembled a larger liquefaction case history database than ever before, and used high order probabilistic tools to regress empirical correlation of liquefaction potential. Moreover they developed a complex formula for stress reduction factor based on the statistical analysis of 2153 site response analyses. Idriss and Boulanger had revised Cetin's database and found that misinterpretation of 8 case histories had considerably pushed Cetin's CRR curve toward a more conservative direction (Fig. 1). Based on this revised database and relying more on theoretical considerations of critical state soil mechanics, they presented their own empirical and probabilistic liquefaction potential method [5], [6].

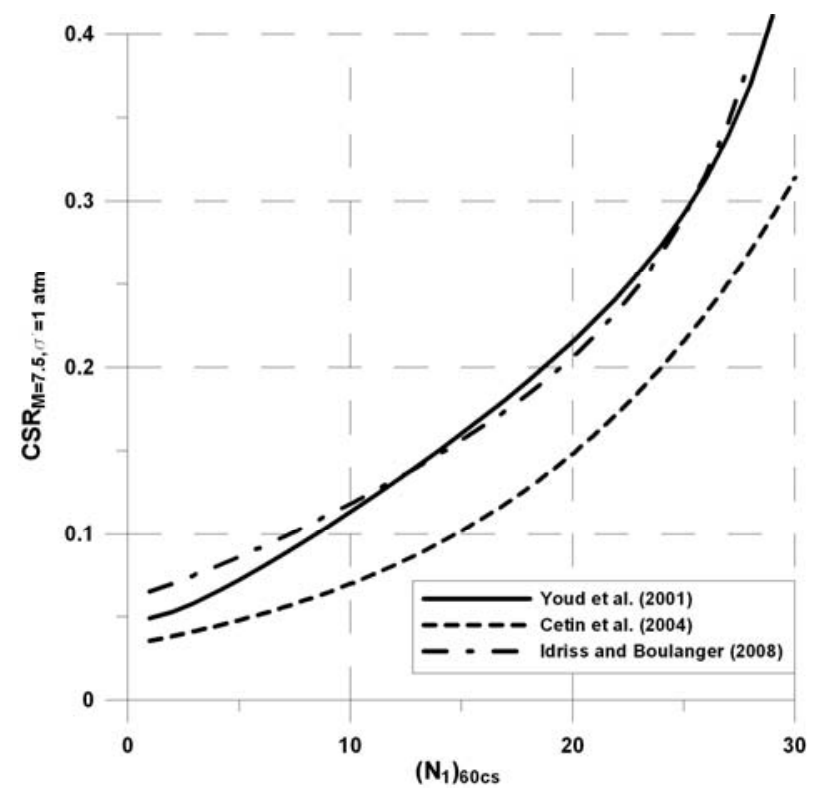

Fig. 1. CRR curves of the examined SPT-based methods (based on [3], [5] and [7]) 
The cyclic stress-based method has several attractive characteristics that made its widespread usage possible. First, it is easy to implement, thus knowing the magnitude and PGA a quick result can be obtained. Second, a considerable amount of knowledge and experience has been gathered since the development of the model's framework in the late ' $60 \mathrm{~s}$ and ' $70 \mathrm{~s}$, and the method has proven to be comfortably conservative. On the other hand, inherent deficiencies in the framework have significant negative effects on the accuracy of the results. It neglects strain amplitudes, which are more responsible for pore pressure generation than stress amplitudes. The entire loading-time history is represented by a single point, namely by the PGA, therefore PGA has to be corrected by a magnitude scaling factor to account for the different number of equivalent loading cycles from different magnitude earthquakes. Thus, two intensity measures (PGA and magnitude) are required increasing the overall uncertainty in the calculation [2].

The cyclic shear strain method is quite similar to the stress-based method in many ways. The loading term, the cyclic shear strain is obtained by dividing cyclic shear stress by the corresponding shear strain modulus [9]. The most important advantage of this method is that excess pore pressure is generated as a result of loose soils' tendency for densification under shaking. So, pore pressure generation is affected much more by shear strain than shear stress. Excess pore pressure ratio can be estimated from a given intensity measure with greater certainty in the case of cyclic strain-based method compared to cyclic stress-based method. However, the loading part has a huge disadvantage that limited, its widespread use in engineering practice. In the current state of knowledge it is not possible to accurately estimate shear strains due to earthquake loading, consequently its predictability is very poor [2].

Energy related methods are a relatively new concept. The approach originated from the observation that hysteretic dissipated energy can be related to volumetric strain and thus pore pressure generation [10]. There have been several proposals for estimating dissipated energy both directly from earthquake source parameters, and from site intensity measures like Arias intensity $\left(I_{a}\right)$ and CAV. Arias intensity and CAV have the advantage that they reflect frequency content, amplitude and duration of the ground motion, however their application is limited due to the lack of experience and verification.

The Arias intensity-based method presented by Kayen and Mitchell [11] is a promising alternative to replace stress-based methods because its correlation to pore pressure build up is stronger than PGA's, however its predictability is poorer. As a new intensity measure for liquefaction evaluation, Kramer and Mitchell introduced the cumulative absolute velocity with a $5 \mathrm{~cm} / \mathrm{s}$ threshold limit $\left(\mathrm{CAV}_{5}\right)$ in [12]. Having examined $\sim 300$ intensity measures they found that excess pore pressure generation in potentially liquefiable soils is considerably more closely related to $\mathrm{CAV}_{5}$ than to any other intensity measures. Moreover its predictability was also found to be within an acceptable limit. Both Arias and $\mathrm{CAV}_{5}$ intensity measures can be calculated from the acceleration time history:

$$
I_{a}=\frac{\pi}{2 g}\left[\int_{0}^{t_{0}} a_{x}^{2}(t) \mathrm{d} t+\int_{0}^{t_{0}} a_{y}^{2}(t) \mathrm{d} t\right]
$$




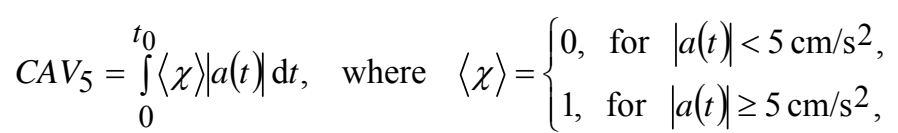

where: $t_{0}$ is the duration of earthquake shaking; $a_{x}$ and $a_{y}$ are the perpendicular components of horizontal ground acceleration. It can be shown that the both the Ariasintensity and CAV have very similar physical meaning [13].

Both Arias intensity and $\mathrm{CAV}_{5}$ are integral parameters, so both of them consider all amplitude peaks, not just the highest one. Moreover they are sensitive to the duration of shaking, and as pore pressure builds up progressively during the motion they can better track the rise of excess pore pressure. In addition $\mathrm{CAV}_{5}$ is featured with a threshold $5 \mathrm{~cm} / \mathrm{s}$ limit, which corresponds to the laboratory observation that a threshold limit shear strain must be exceeded before pore pressure is generated [12].

\section{Loading parameters and site characteristics}

The first step in a liquefaction potential evaluation was the determination of loading conditions. In this paper, for the sake of comparability, an earthquake with the following parameters had been selected for all calculations: $M_{w}=6.0$ magnitude, $15 \mathrm{~km}$ epicentral distance, $10 \mathrm{~km}$ focal depth and strike slip mechanism. An earthquake with these parameters gives the main contribution to liquefaction hazard of Paks NPP site.

In the next step, attenuation relationships were chosen in order to calculate the actual intensity measures at the site from the outlined source parameters. To maintain consistency those attenuation relationships were selected that had been developed from similar databases, had similar functional forms and concerned similar site conditions. As the main goal of this paper is the comparison of empirical methods, and not the evaluation of liquefaction potential of Paks NPP site, amplification effect of the soft soil layers have been neglected during the determination of site intensity measures.

Attenuation relationship for $\mathrm{CAV}_{5}$ was developed by Kramer and Mitchell [12] from the PEER strong motion database. The selected ground motions were compiled to approximately correspond to that used in the Abrahamson and Silva attenuation law [14] for acceleration values. For this reason, acceleration at the site was calculated with a refined version of the Abrahamson and Silva relationship [15]. The functional form of the $\mathrm{CAV}_{5}$ attenuation is in the same form as Travasarou's attenuation relationship [16] for Arias intensity, and uses a similar source database, thus Arias intensity was calculated with this method at the site. Kayen and Mitchell [11] also presented an attenuation law for their Arias intensity-based method, and since this equation was recommended by the authors it was also considered in the following calculations. A summary of the different attenuation relationships and the resulting intensity values are shown in Table I.

Regarding resistance against liquefaction, the Paks site is located on a fluvial deposit of the Danube River. A typical soil profile consists of $2 \mathrm{~m}$ artificial fill overlying a $6 \mathrm{~m}$ thick Holocene stratum, mainly sand and silt. Below that is situated a $7 \mathrm{~m}$ thick Pleistocene poorly-graded sand. The grain size of this layer increases with depth and at 
a $15 \mathrm{~m}$ depth, the main fraction transitions to gravel. The bedrock is assumed to be the stiff Pannonian deposit starting at $27 \mathrm{~m}$ depth. The groundwater level was assumed to be $8 \mathrm{~m}$ deep [17]. In the mid-90's, a comprehensive geotechnical survey was conducted to better understand site conditions and to reevaluate seismic safety. The survey focused on a research site just north to the reactor buildings. To allow comparison of different in situ methods, SPT, CPT and shear wave velocity measurements were selected as close to each other as possible (within a radius of $5 \mathrm{~m}$ ) and the assumption was made that they explored the same soil conditions. Comparative assessment of different cyclic stressbased methods have been presented in a conference paper by the authors [18], thus only the selected SPT record is shown here (Fig. 2).

Table I

Attenuation relationships for different intensity measures and their mean values at the site of comparison

\begin{tabular}{|c|c|c|c|c|}
\hline Earthquake & \multicolumn{3}{|c|}{$M_{w}=6$, Distance $=15 \mathrm{~km}$, Depth $=10 \mathrm{~km}$, strike slip } \\
\hline Intensity measure & \multicolumn{2}{|c|}{ Arias intensity } & $\mathrm{CAV}_{5}$ & PGA (a $\left.\mathrm{a}_{\max }\right)$ \\
\hline $\begin{array}{c}\text { Attenuation } \\
\text { relationship }\end{array}$ & $\begin{array}{c}\text { Travasarou } \\
(2003)\end{array}$ & $\begin{array}{c}\text { Kayen } \\
(1997)\end{array}$ & $\begin{array}{c}\text { Kramer and } \\
\text { Mitchell } \\
(2006)\end{array}$ & $\begin{array}{c}\text { Abrahamson and } \\
\text { Silva (2008) }\end{array}$ \\
\hline Mean value & $0.157 \mathrm{~m} / \mathrm{s}$ & $0.488 \mathrm{~m} / \mathrm{s}$ & $1.69 \mathrm{~m} / \mathrm{s}$ & $1.40 \mathrm{~m} / \mathrm{s}^{2}$ \\
\hline
\end{tabular}
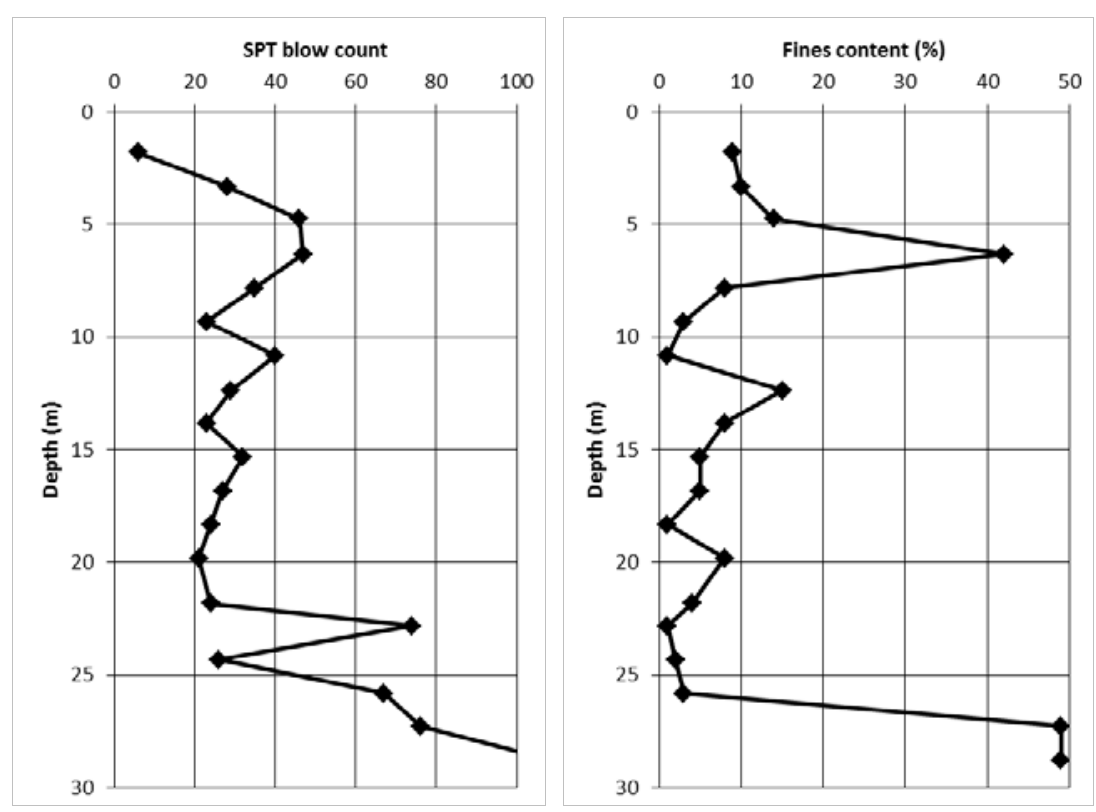

Fig. 2. Raw blow-count and fines content of the selected SPT profile 
As several factors influence SPT blow-counts, raw field values should be modified with correction factors to take into account the effect of hammer energy, rod length, borehole diameter and sampling method. In this study the recommendations of Youd et al. [3] were followed. Corrections for overburden pressure and fines content were implemented as required by each method.

\section{Comparison of the results}

As the described attenuation relationships were all developed with probabilistic tools, evaluation of their standard deviations became possible. As it is shown in Fig. 3, among the three intensity measures, PGA has the lowest standard deviation, while Arias intensity has the highest. As standard deviation indicates the confidence level of one's calculated values, it reflects the predictability of intensity measures. Although PGA is the most predictable it has to be supplemented with a magnitude scaling factor to account for the duration of earthquake, thus the overall uncertainty in predicting the loading parameters of stress-based methods is higher than for $\mathrm{CAV}_{5}$. These results support the findings of Kramer and Mitchell [12].

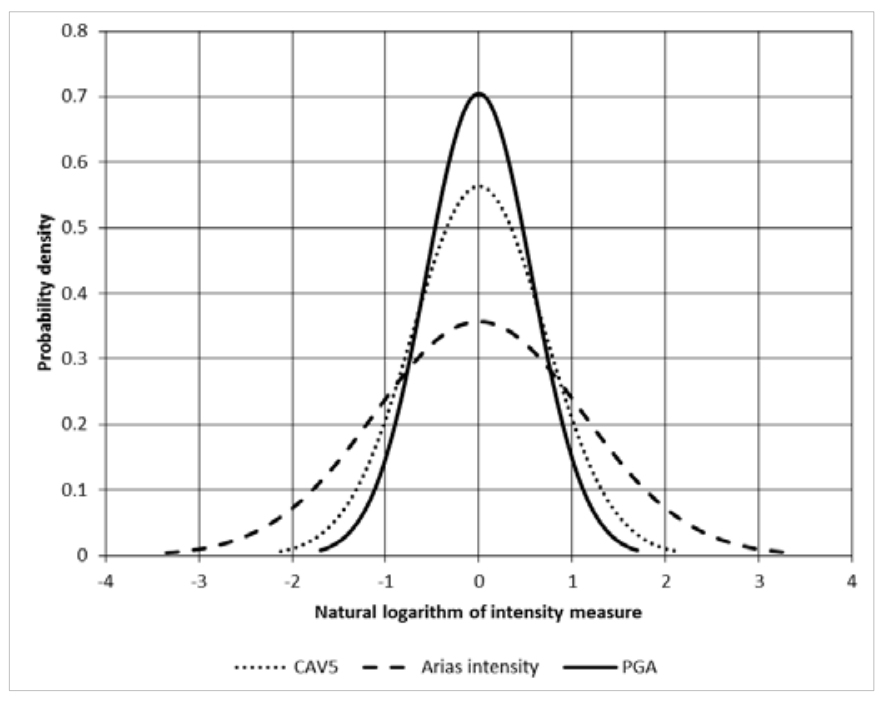

Fig. 3. Probability density functions (adjusted to zero) of the three intensity measures

Using the above methods and mean values, factors of safety against liquefaction were calculated for the profile.

As Fig. 4 shows considerable differences can be observed in the results and significantly different conclusion can be drawn about liquefaction hazard depending on the selected method. The high variability in factor of safety arises partly from the attenuation relationships, partly from the liquefaction potential evaluation methods, and partly from the nature of calculating factor of safety. It is primarily a deterministic tool 
being applied to probabilistic methods. Nonetheless, it is useful as an indicator of a liquefaction threshold.

As it is clearly seen in Fig. 4, the $\mathrm{CAV}_{5}$-based method yields the lowest factor of safety values in the critical layer. This would support, the necessity of further verification of the method. The least conservative result was provided by the Arias intensity method with Travasarou's attenuation. This is mainly due to the attenuation relationship, which compared to Kayen's relationship, predicted a relatively low value of Arias intensity at the site.

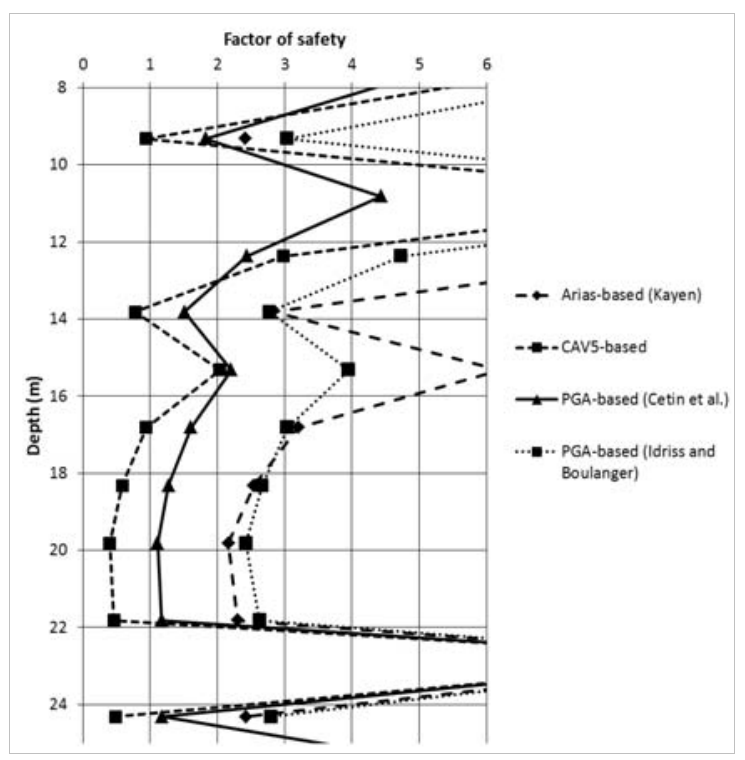

Fig. 4. Comparison of different methods' factors of safety calculated from the same earthquake source parameters. $\mathrm{CAV}_{5}$ values predict the lowest values, Arias-based the highest

An opposite case, when uncertainty arises not from the attenuation law, but from the liquefaction potential evaluation method, is reflected by the cyclic stress-based methods. As it can be seen in Fig. 4 and Fig. 5 even if the same input loading parameters are used, the results can be significantly different. The difference between the factors of safety of Cetin's and Idriss and Boulanger's method is mostly due to the different layout of their CRR threshold curves as it can be seen in Fig. 1.

Factor of safety values shown in Fig. 4 were calculated using the mean values of the corresponding attenuation relationships. As these relationships were derived with careful statistical analysis of earthquake databases, they also allow probabilistic estimation of the intensity measures at a site.

In Fig. 5 factor of safety of the cyclic stress-based methods are shown for the mean acceleration and for the $85^{\text {th }}$ percentile acceleration value. The higher percentile means higher confidence of the estimation of the magnitude that will not be exceeded. It also means a higher PGA that shifts the factor of safety in a conservative direction.

Pollack Periodica 11, 2016, 1 
Obviously for higher acceleration, a lower factor of safety is obtained. It can be noted that the difference between Cetin's and Idriss and Boulanger's method is also decreased, that is due to the functional forms of the CRR curves. It can be concluded, if intensity measures are determined with a higher confidence level, differences in factors of safety between the results based on the same intensity measure will be less significant.

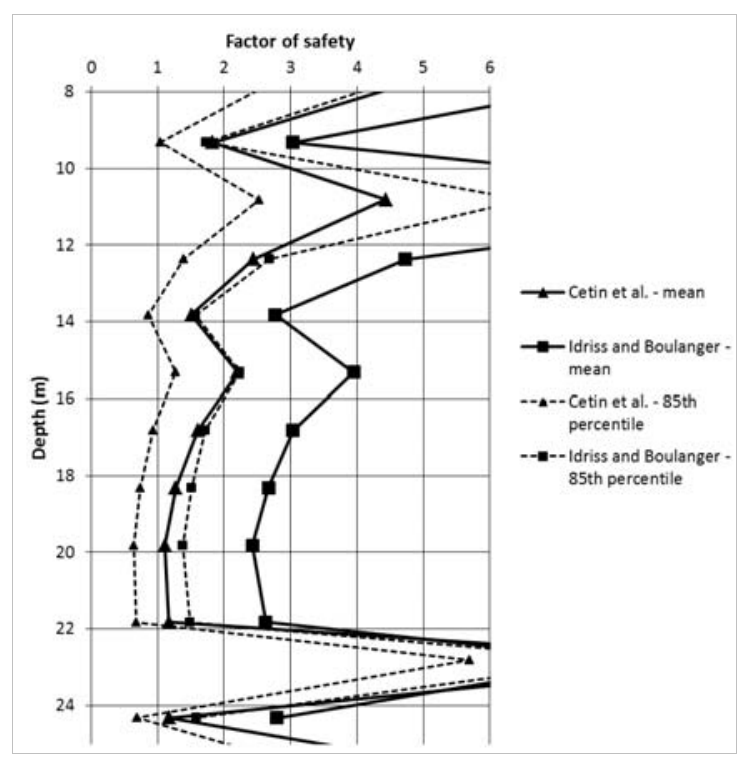

Fig. 5. Comparison of cyclic stress-based methods for mean and $85^{\text {th }}$ percentile values of acceleration. The $85^{\text {th }}$ percentile values are in closer agreement

As it was discussed earlier, the stress reduction factor takes into account the amplification of shear stress in a flexible soil column. Similar reduction factors are included in the energy-based methods too.

The soil parameters available for the site of this study enabled the performance of a nonlinear site response analysis. The site response can be estimated with simplified equations as well. Among these a simple, only depth-dependent $r_{d}$ of Liao and Whitman [19], the magnitude- and depth-dependent factor of Idriss [20] and more complex forms of Cetin with and without a shear wave velocity term [7], [21] have been used for comparison with the site-specific result (Fig. 6).

Fig. 6 shows remarkable scattering in the values of $r_{d}$. It has to be noted, that the two extreme curves are obtained by the two equations of Cetin having almost the same functional form. This result can be explained by the relatively high average shear wave velocity of the upper $12 \mathrm{~m}$ at the site. At the Paks site, beneath the reactor main buildings, a relatively stiff Holocene silty-sand layer overlies the liquefiable layers. The average shear wave velocity, $v_{s}$ in this upper $12 \mathrm{~m}$ layer is more than $250 \mathrm{~m} / \mathrm{s}$. As the database for deriving the $r_{d}$ relationships of Cetin included sites with $v_{s}=120-250 \mathrm{~m} / \mathrm{s}$, 
the high velocity of the examined site shifts the $r_{d}$ relationship in a more conservative direction. On the other hand, the equation excluding $v_{s}$ term was developed using data for sites with $v_{s} \sim 160 \mathrm{~m} / \mathrm{s}$. Therefore the result obtained by this formula, fits better to the site-specific stress reduction factor. As different $r_{d}$ approaches can yield to considerably different results, thorough consideration is recommended before using them, especially when there is a stiffer layer near the surface that can distort the stress reduction factor.

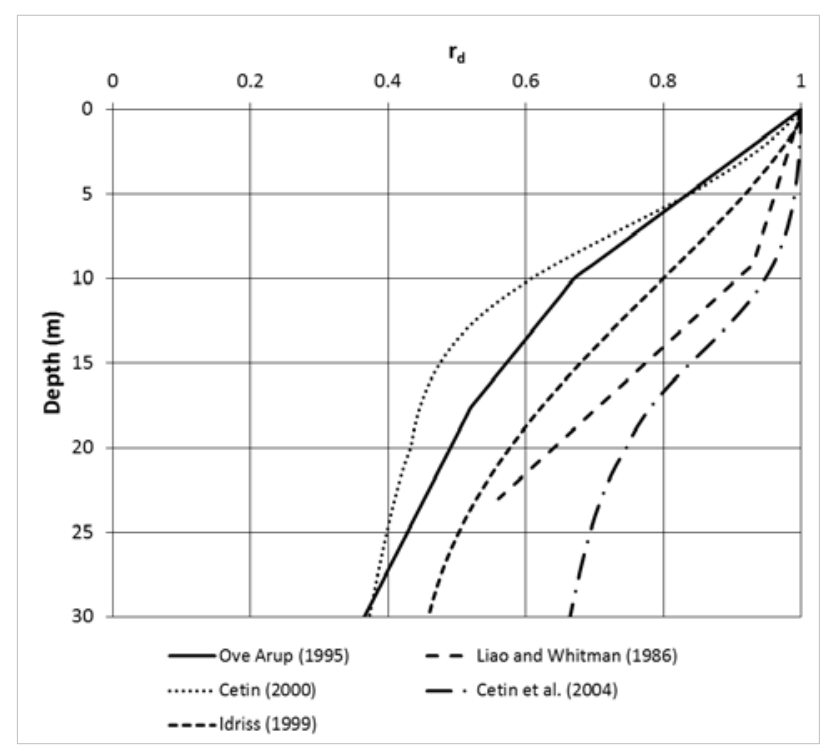

Fig. 6. Comparison of stress reduction factors $\left(r_{d}\right)$ determined with site response analysis (Over Arup) and simplified equations of different authors

Because of this high level of uncertainty, it might be asked: which method is the closest to reality? Unfortunately, an objective answer cannot be given for this question, but the problem can be treated with the application of logic tree methodology described in detail in Győri et al. [22].

\section{Summary}

Analysis of the consequences of earthquake-induced soil liquefaction on the safety of nuclear power plants requires specific considerations, especially if the liquefaction is assumed to be beyond a design-basis hazard. A realistic evaluation of the soil liquefaction is needed for the design of accident management measures. Systematic comparison of empirical liquefaction prediction methods has been performed in the paper for better estimation of the liquefaction susceptibility. The methods compared are based either on the cyclic stress or on the Arias intensity and $\mathrm{CAV}_{5}$. For realistic comparisons the input loading parameters, the intensity measures were calculated for the same size of earthquake, selected for the Paks site. The attenuation relationships 
were carefully chosen to calculate intensity measures. The resistance has been evaluated using an SPT record obtained on a test-field near the reactor buildings. Profiles of factor of safety with depth were calculated via indicated methods. The results comply with the findings of other authors, namely, the acceleration and $\mathrm{CAV}_{5}$ can be predicted with more certainty from source parameters than the Arias intensity. It should be noted that, in the cyclic stress-based methods, the acceleration should be supplemented with a magnitude scaling factor, thus the overall uncertainty in predicting the loading parameters of stress-based methods are higher than that for $\mathrm{CAV}_{5}$.

Comparison of factors of safety computed from the empirical methods shows that significant differences can be observed in the results and significantly different conclusions can be drawn about liquefaction hazard depending on the selected method. The high uncertainty in factor of safety partly arises from the attenuation relationships, and partly it is inherent to the liquefaction evaluation methods. As the attenuation relationships were derived with statistical analysis of earthquake databases, they also allow probabilistic estimation of the intensity measures at a site. Higher confidence in the level of non-exceedance of the earthquake magnitude will result in higher value of the intensity measure. Due to the functional forms of CRR curves it can be concluded, if accelerations or intensity measures are determined with higher confidence level, the differences in factors of safety obtained via methods based on the same intensity measure will decrease.

One of the most important components of empirical methods is the depth reduction coefficient, which accounts for the nonlinear ground response in a soil column overlying the depth of interest. This can be estimated most accurately with a detailed site response analysis; but simplified equations also exist to approximate this reduction factor. Comparison of site-specific analysis and results of stress-based simplified equations showed that variability in the simplified equations can be remarkable, especially where a stiffer layer can be found near the surface. Thus for high-risk facilities performance of a site response analysis is highly recommended.

\section{References}

[1] Katona T. J. Safety assessment of the liquefaction for nuclear power plants, Pollack Periodica, Vol. 10, No. 1, 2015, pp. 39-52.

[2] Mayfield R. T. The return period of soil liquefaction, $P h D$ Dissertation, University of Washington, 2007.

[3] Youd T. L., Idriss I. M., Andrus R. D., Arango I., Castro G., Christian J. T., Dobry R., Finn W. D. L., Harder L. F., Hynes M. E., Ishihara K., Koester J. P., Liao S. S. C., Marcuson W. F., Martin G. R., Mitchell J. K., Moriwaki Y., Power M. S., Robertson P. K., Seed R. B., Stokoe K. H. Liquefaction resistance of soils: summary report from the 1996 NCEER and 1998 NCEER/NSF workshops on evaluation of liquefaction resistance of soils, Journal of Geotechnical and Geoenvironmental Engineering, Vol. 127, No. 10, 2001, pp. 817-33.

[4] Seed H. B., Idriss I. M. Simplified procedure for evaluating soil liquefaction potential, Journal of the Soil Mechanics and Foundations Division, ASCE, Vol. 97, No. SM9, 1971, pp. 1249-1273.

[5] Idriss I. M., Boulanger R. W. Soil Liquefaction during Earthquakes, Monograph MNO-12, Earthquake Engineering Research Institute, Oakland, CA, 2008. 
[6] Boulanger R. W., Idriss I. M. CPT and SPT based liquefaction triggering procedures, Report No. UCD/CGM-14/01, University of California, Davis, CA, 2014.

[7] Cetin K. O., Seed R. B., Der Kiureghian A., Tokimatsu K., Harder L. F., Kayen R. E., Moss R. E. S. Standard penetration test-based probabilistic and deterministic assessment of seismic soil liquefaction potential, Journal of Geotechnical and Geoenvironmental Engineering, ASCE, Vol. 130, No. 12, 2004, pp. 1314-1340.

[8] Moss R. E. S., Seed R. B., Kayen R. E., Stewart J. P., Der Kiureghian A., Cetin K. O. CPTbased probabilistic and deterministic assessment of in situ seismic soil liquefaction potential, Journal of Geotechnical and Geoenvironmental Engineering, ASCE, Vol. 132, No. 8, 2006, pp. 1032-1051.

[9] Dobry R., Ladd R. S., Yokel F. Y., Chung R. M., Powell D. Prediction of pore water pressure buildup and liquefaction of sands during earthquakes by the cyclic strain method, NBS Building Science Series, National Bureau of Standards, Gaithersburg, MD, 1982.

[10] Nemat-Nasser S., Shokooh A. A unified approach to densification and liquefaction of cohesionless sand in cyclic shearing, Canadian Geotechnical Journal, Vol. 16, No. 4. 1979, pp. 649-678.

[11] Kayen R. E., Mitchell J. K. Assessment of liquefaction potential during earthquakes by Arias intensity, Journal of Geotechnical and Geoenvironmental Engineering, ASCE, Vol. 123, No. 12, 1977, pp. 1162-1174.

[12] Kramer S. L., Mitchell R. A. Ground motion intensity measures for liquefaction hazard evaluation, Earthquake Spectra, Vol. 22, No. 2, 2006, pp. 413-438.

[13] Katona T. J., Tóth L. Damages indicators for post-earthquake condition assessment, Acta Geodaetica et Geophysica, Vol. 48, No. 3, 2013, pp. 333-345.

[14] Abrahamson N. A., Silva W. J. Empirical response spectral attenuation relations for shallow crustal earthquakes, Seismological Research Letters, Vol. 68, 1997, pp. 94-127.

[15] Abrahamson N. A., Silva W. J. Summary of the Abrahamson \& Silva NGA Ground-Motion Relations, Earthquake Spectra, Vol. 24, No. 1, 2008, pp. 67-97.

[16] Travasarou T., Bray J. B., Abrahamson A. Empirical attenuation relationship for Arias Intensity, Earthquake Engineering and Structural Dynamics, Vol. 32, No. 7, 2003, pp. $1133-1155$.

[17] Ove Arup \& Partners, Paks NPP site investigation for site response and liquefaction potential, Report, Archives, Paks NPP, 1995.

[18] Bán Z., Katona T. J., Mahler A. Comparison of empirical liquefaction potential evaluation methods (in Hungarian), Proceedings of Geotechnika, Ráckeve, Hungary, 13-15 October 2014, pp. 1-15.

[19] Liao S. S. C., Whitman R. V. Catalogue of liquefaction and non-liquefaction occurrences during earthquakes, Research Report, Department of Civil Engineering, Massachusetts Institute of Technology, Cambridge, MA, 1986.

[20] Idriss I. M. An update to the Seed-Idriss simplified procedure for evaluating liquefaction potential, Proceedings of TRB Workshop on New Approaches to Liquefaction, Publication No. FHWARD-99-165, Federal Highway Administration, 1999.

[21] Cetin K. O. Reliability-based assessment of seismic soil liquefaction initiation hazard, $P h D$ Dissertation, University of California, Berkeley, CA, 2000.

[22] Győri E., Tóth L., Gráczer Z., Katona T. Liquefaction and post-liquefaction settlement assessment - a probabilistic approach, Acta Geodaetica et Geophysica Hungarica, Vol. 46, No. 3, 2011, pp. 347-369. 